\title{
AN EXPLORATORY STUDY OF THE INTERLANGUAGE PRAGMATIC COMPREHENSION OF YOUNG LEARNERS OF ENGLISH
}

\author{
Cynthia Lee
}

\begin{abstract}
This paper describes the developmental pattern of the interlanguage pragmatic comprehension of young learners of English based on their performance in a multiple-choice comprehension exercise consisting of five direct and indirect speech acts (requesting, apology, refusal, compliment and complaint) in contextualised dialogues, supplemented with information on their processing strategies as elicited from their verbal protocols. The findings contribute to the literature on the interlanguage developmental pragmatics of young learners, an area on which research literature is scarce.

Three groups of seven-, nine- and twelve year-old Cantonese learners of English participated. The overall mean comprehension scores of the three groups increased steadily, but the difference in the scores across groups was only statistically significant between the seven- and nine-year-olds. All of the learners performed well in the comprehension of direct speech acts, but the seven- and nine-year-old learners encountered problems in comprehending indirect speech acts, particularly indirect refusals, compliments and complaints. Their performance and processing strategies provide some evidence for the development of direct and indirect speech act comprehension in learning a second language - from relying on literal meaning or the semantic congruence between meaning and expression to other strategies, such as speaker intention and contextual clues, as they transit from early to middle childhood.
\end{abstract}

Keywords: Interlanguage pragmatic comprehension; Speech act; English.

\section{Introduction}

Interlanguage pragmatics (ILP) is a burgeoning area in second language (hereafter L2) acquisition. The discipline of ILP is defined by Kasper and Dahl (1991) as "the study of non-native speakers' acquisition, comprehension and production of pragmatics". Bardovi-Harlig (2002: 185) comments that ILP "is not a new area, just an underdeveloped one”, and recommends that its central research theme be the development of pragmatic knowledge. Within ILP development, however, research has been dominated by production-oriented studies (Rose 2009) and comprehension is "the least well represented, with only a handful of studies done to date" (Kasper and Rose 2002: 118). Several recent ILP studies that are presented in the following section have 
found a co-relationship between the comprehension of implied meaning among adult L2 learners and certain social and psychological variables, including the learners' proficiency level (e.g., Kasper 1984; Yamanaka 2003), language contact with speakers of the target language (e.g., Schmidt 1983; Bouton 1992; 1994; 1999; Achiba 2003), comprehension speed and accuracy (e.g., Cook and Liddicoat 2002; Taguchi 2005). The studies also explain the differences or growth with reference to corresponding processing mode (e.g., top-down and bottom-up) and strategies (e.g., keyword inferencing) used by these learners. Nevertheless, the focus of these studies is on the association between various social, linguistic and psychological variables and one group of learners, that is the adult L2 learners at a designated point of time. None of them have described or compared the ILP comprehension ability, development and corresponding processing strategies of different age groups of learners, particularly young L2 learners. This study fills the research gap by attempting to describe the developmental pattern of interlanguage pragmatic comprehension and the processing strategies of young L2 learners at different stages of childhood in an orderly manner rather than attempting to explain the developmental pattern in relation to proficiency or language exposure, a neglected area in ILP development.

\section{ILP comprehension studies: A brief review}

Research on ILP began in the 1970s. Since the 1980s, both cross-sectional and longitudinal studies have explored the variables that affect ILP development, production and acquisition, including social affective factors (Schumann 1978), grammar (Walters 1980), pragmatic transfer (Olshtain 1983), length of residence, time spent studying abroad and duration of language contact (e.g., Schmidt 1983; Bouton 1992, 1994, 1999; Achiba 2003). However, within the ILP literature, comprehension studies are relatively few.

The most recent studies on ILP and comprehension focus on adult L2 learners, and specifically on testing their ability to interpret the interlocutor's intention and implied meaning of face-threatening acts such as conventional and non-conventional requests or refusals (e.g., Carrell 1982; Cook and Liddicoat 2002; Taguchi 2008b) or their comprehension accuracy and speed over a designated period in a cross-sectional experiment according to their proficiency levels (e.g., Cook and Liddicoat 2002; Taguchi 2005). In such studies, researchers invite learners to role play or answer listening questions according to their proficiency levels (Kasper 1984; Cook and Liddicoat 2002; Yamanaka 2003; Taguchi 2005), compare their comprehension results and speed with native English speakers (Holtgraves 2007), or re-test the development of their comprehension ability over a certain interval or after a period of language contact (Bouton 1992, 1994, 1999; Taguchi 2007, 2008a, 2008b). These studies find that accuracy rate and processing speed vary with L2 learners' proficiency level, length of residence and language contact. High-proficiency L2 learners are generally more able to interpret implied meaning than low-proficiency L2 learners. The comprehension performance of the former is sometimes on a par with or as accurate as that of native speakers (Taguchi 2002). On the other hand, the comprehension performance of the latter is usually lower than that of native speakers (Yamanaka 2003). Language contact and exposure may help L2 learners to better comprehend conversational implicatures except those which are culture-specific (Bouton 1994, 1999), and improve 
comprehension speed but not accuracy in comprehending indirect opinion (Taguchi 2008a). In other words, there is no guarantee for an overall improvement in the comprehension of implied meaning. Taguchi (2002) identifies five adult English learners' reception strategies, that is, paralinguistic cues, the adjacency pair rule, background knowledge and experience, keyword inferencing, logical reasoning and speaker intention. She also found that low- and high-proficiency adult learners of English adopted different inferential strategies. The low-proficiency group used more keyword inferencing and background experience, whereas the high-proficiency group attended more to paralinguistic cues, the adjacency pair rule and speaker intention. Researchers have explained the performance of adult learners from different perspectives, including the frame-theoretical approach (Kasper 1984), language-processing model (Bialystok 1991) and relevance theory (Sperber and Wilson 1995). However, the general view is that low-proficiency adult learners rely too heavily on bottom-up processing (Kasper 1984) and have difficulty controlling attention and analysing linguistic and contextual knowledge (Cook and Liddicoat 2002). Further, their inadequate cultural background knowledge (Bouton 1992, 1994, 1999) and undeveloped automatic speech act recognition as L2 learners (Holtgraves 2007) also impede their comprehension of implied meaning.

These results on the comprehension ability of adult L2 learners are not surprising given that adults have acquired and developed their L1 discourse and linguistic competence that allows them to control attention, integrate multiple sources of information and analyse L2 linguistic and contextual knowledge more effectively, compared with language learners, particularly young learners who are in a growing state in which they continue to be exposed and react to various experiences (Bialystok 1991, 2001). However, the research literature on the pragmatic comprehension ability, processing strategies and development of young L2 learners is comparatively scarce. Thus, to better understand their comprehension competence, it is worth re-visiting the language development of L1 children, which may shed light on that of L2 young learners. It is this that we turn to next.

\section{Pragmatic competence and development of children: A brief review}

Young children's pragmatic comprehension and production abilities develop and will change with age when their desires and scope of linguistic and communicative competence increase. What has been documented in child language literature are that there is an 'increasing sensitivity to the perspective of the listener' and 'the move away from reliance on the immediate situational context towards greater reliance on non-situated knowledge' (Ochs 1979: 9). The earliest stage of language use below two years old begins with referring to an object or making a one-word response to request an action, an adult's attention or an answer from an adult (Bucciarelli, Colle and Bara 2003). Other speech acts such as offers, greetings and rejections can be carried out through reaching, waving, pushing away and heading shaking (Ochs 1979). The same action is usually contextualized and successful communication depends heavily on the interlocutor's ability to interpret or infer from the gesture in context. Nevertheless, this language ability increases drastically from 18 months to six years to the production of two- or three-word grammatical utterances, then to learning the discourse rules of interactions between the ages of three and five years with the help of adults in terms of 
interaction and context (McLean and Snyder-McLean 1999). Most studies suggest that children below the age of five have an easier time understanding direct requests than indirect requests because they are rarely confronted with examples of non-literal utterances; rather they are learning from direct experience and developing their understanding of cause and effect (Mckay 2006). Children in early childhood, that is, between the ages of six and nine years, gradually come to better understand and produce indirect speech acts as they become more aware of other ways to express intention and lose the default assumption that there is semantic congruence between a literal utterance and a speaker's intended meaning. For instance, child directive form developed from explicitness to imbeddings - telegraphic directives, limited routines, imbeddings and structural modifications to hints without explicit imperatives (Ervin-Tripp 1977). Children of this age are also more able to engage in a connected discourse on a topic, such as telling a story. A higher level of mastery of both production and comprehension is achieved in middle childhood, that is, from nine to thirteen years old. Children of this age achieve greater competence in pragmatics, and can comprehend indirect speech acts such as irony, puns, requests, humour and idioms; maintain a longer conversational turn and talk about a topic for a longer time; and provide more appropriate responses in conversational interaction after mastering the appropriate cultural knowledge (Menyuk and Brisk 2005; Byrnes and Wasik 2009). Following natural cognitive and language development processes, young children's formulaic system and rule-based system (Skehan 1989) are certainly less resourceful than those of adults, which explains their different cognitive processes in language learning. Compared with adult language learners, young language learners rely more heavily on the formulaic system in both L1 and L2, and may not refer much to the rule-based system, as they are still developing their metalinguistic ability (Mckay 2006).

To address the identified research gap, this study aims to describe young L2 learners' pragmatic ability to comprehend both direct and indirect speech acts by referring to their cognitive processing strategies as derived from their retrospective verbal protocols. Two broad research questions are raised.

1. What is the pragmatic comprehension ability of young L2 learners at different stages of childhood? What evidence is there of significant difference in their interlanguage pragmatic comprehension ability?

2. How do young L2 learners at different stages of childhood comprehend direct and indirect speech acts?

\section{Background information}

\subsection{Participants - Language learning experience}

The study participants were Hong Kong Cantonese children in early and middle childhood who were learning English as a subject at school. In Hong Kong, 90\% of the population is Cantonese, speaks Cantonese (a Yue spoken dialect) and writes standard written Chinese in formal and official documents, although a written form of Cantonese is adopted by some newspapers (Snow 2004; Yip and Matthews 2007). In Hong Kong, children begin their formal education at around three years old, and most spend two to three years in nursery and kindergarten classes. This is the period during which they learn the English alphabet, words and phonics under formal instruction. At age six, they 
move to primary schools and complete the six years of compulsory primary education. At age 12, they move to secondary schools and complete another six years of secondary education ${ }^{1}$ in which the first three years of education is compulsory. Children are free to study in one of the four main types of school - government, government subsidised, government direct subsidised and private schools - all of which follow and offer the same curriculum prepared by the Curriculum Development Council but differ in the way the school is funded, pedagogic preference and medium of instruction. The great majority of primary schools, including the three participating schools adopt Cantonese as the medium of instruction, and $17 \%$ to $21 \%$ of lesson time is allocated to the English Language subject (Curriculum Development Council 2004: 111), or about five to eight periods per week (each period is usually 35 minutes long) (Curriculum Development Council 1997: 128). English classes are supplemented with oral lessons conducted by native English teachers hired under the government's Native English Teachers Scheme, and other co-curricular or extra-curricular English activities (Curriculum Development Council 2004: 109-110). Only a few elite primary schools adopt English as the medium of instruction.

English language teaching in Hong Kong primary schools is monitored by the English Language Curriculum Guide (Primary 1-6), an official document prepared by the Curriculum Development Council (2004) and recommended for use in schools by the Education and Manpower Bureau. According to the document, the six years of primary education is divided into two Key Stages: Key Stage 1 runs from Primary 1 to 3 (i.e., 6 to 8 years old) and Key Stage 2 from Primary 4 to 6 (i.e., 9 to 12 years old). In terms of interpersonal communication, the document recommends teaching some speech acts and corresponding formulaic expressions that are congruent with their functions at the two Key Stages, including those that express approval and compliment (e.g., Good/Well done!), use modals and interrogative questions to ask for permission (e.g., Can I), express apologies (e.g., I'm sorry) and accept or decline offers, requests and invitations (e.g., No thank you/Yes please) at Key Stage 1 for 6-8 year-old learners (Curriculum Development Council 2004: 45). Additional speech acts such as disagreeing, suggesting or showing concern and corresponding linguistic devices are recommended for 9-12 year-old learners at Key Stage 2 (Curriculum Development Council 2004: 46).

The 176 participants in the study were Cantonese English learners from three government subsidised co-educational primary schools located on the Kowloon Peninsula, Hong Kong Island and the New Territories, ${ }^{2}$ respectively. Sixty-four seven-year-old Primary 2, 62 nine-year-old Primary 4 and 50 twelve-year-old Primary 6 L2 learners with an average age of 7;5, 9;4 and 11;8 years old, respectively, were selected randomly from each school to represent the different learning periods in the two Key Stages. According to information from the schools, all of the participants had finished two to three years of kindergarten education and had learnt some simple English words before joining the schools. They came from middle-class families in Hong Kong. The participants were chosen randomly by the school according to age, rather than their school English test results. The following tables summarise the profiles

1 The new 6-year secondary education was implemented in 2009. Prior to 2009, the old secondary education comprises 5 years and 2 years of matriculation.

${ }^{2}$ Hong Kong consists of three main parts: Kowloon Peninsula, Hong Kong Island and the New Territories. 
of the schools and participants.

Table 1: School profile

\begin{tabular}{|c|c|c|c|}
\hline Primary school & Type of school & Location & Medium of instruction \\
\hline School A & $\begin{array}{l}\text { Government } \\
\text { school }\end{array}$ & Hong Kong Island & Cantonese \\
\hline School B & $\begin{array}{l}\text { Government direct subsidised } \\
\text { school }\end{array}$ & Kowloon & Cantonese \\
\hline School C & $\begin{array}{l}\text { Government direct subsidised } \\
\text { school }\end{array}$ & New Territories & Cantonese \\
\hline
\end{tabular}

Table 2: Participant profile

\begin{tabular}{|c|c|c|c|c|}
\hline Group & $\mathrm{Age}^{3}$ & Level & English learning experience & $\begin{array}{l}\text { Total number of } \\
\text { subjects }\end{array}$ \\
\hline \multicolumn{5}{|c|}{ Primary students } \\
\hline 1 & 7 & Primary 2 & Around 4 years, since kindergarten & 64 \\
\hline 2 & 9 & Primary 4 & Around 6 years, since kindergarten & 62 \\
\hline \multirow[t]{2}{*}{3} & 12 & Primary 6 & Around 8 years, since kindergarten & 50 \\
\hline & & & (a) Total number of primary students & 176 \\
\hline
\end{tabular}

\section{Methodology}

The interlanguage comprehension ability of the participants was measured by means of a multiple-choice comprehension exercise that consisted of direct and indirect speech acts. In addition, their processing strategies were elicited largely based on retrospective verbal protocols modified from the introspective verbal protocol or 'think aloud' method for adults (Ericsson and Simon 1987; Cohen 1987) and children (Gu, Hu and Zhang 2005). Both methods complemented each other with the former provided statistical figures and the latter observed the cognitive processes involved in comprehension and language use.

\subsection{Multiple-choice comprehension exercise}

Comprehension exercises that are presented in either verbal or written form in ILP comprehension research focus on indirect speech acts, such as indirect requests and refusals and suggestions. Generally speaking, they have four common features: (1) a scenario or background information about the interlocutors (textual description or video); (2) dialogues between a speaker and a listener; (3) a question (asking what the speaker means or how the hearer feels or thinks about the speaker) and (4) choices (usually four) or probes. Taking into account the ages of the participants and the amount of time allowed by the participating schools for the study, a multiple choice comprehension exercise format that embraced these four features was chosen to cause minimal disturbance to the regular teaching and learning in the schools. The exercise covered five direct and indirect speech acts that have been well researched in

3 The average age of three groups of children are: 7;4, 9;5 and 11;8. For convenience, they are described as 7, 9 and 12 year olds. 
cross-cultural pragmatics and ILP development: requests, apologies, refusals, complaints and compliments. The first four of these are face-threatening acts and the last is a face-saving act (Brown \& Levinson 1987).

As the young L2 learners may not have the supporting language environment to acquire or use the five speech acts English outside the classroom, a preliminary survey ${ }^{4}$ of the contexts in which the young learners had experienced them ${ }^{5}$ in their L1 was conducted. The purpose of the survey was to ensure that the contexts or the topics appeared in the questionnaire were familiar to them, which is crucial in assessment tasks for young language learners (Mckay 2006) as familiarity of information can reduce communicative stress and task difficulty when they encounter them in L2 (Ellis 2003: 223-224). With the assistance of the primary school teachers, 552 speech events in the L1 context that had been written or verbally reported by 40 primary students were successfully collected. The analysis of the L1 speech events showed that they were related to family, home and school affairs, including - but not limited to - breaking something, praise for good results, hitting someone or fighting during recess, complaining about behaviour, copying classmates' homework and so forth. The frequency of each speech event was tallied and the top twelve events were selected as the contexts for the speech acts in the comprehension exercise.

The selected L1 speech events were presented in L2 to represent different social and power hierarchies (i.e., low, high or equal). The speech events were fine-tuned linguistically based on the linguistic devices suggested in the literature (Section 5.2) and the formulaic expressions recommended by the government's official document (Section 4.1) for these groups of learners. Appendix 1 summarises the direct and indirect speech acts, contexts and social variables involved in the questionnaire based on the preliminary survey results. To facilitate the young learners' comprehension, a character called Mei Mei and her peers and family members were developed to perform the direct and indirect speech acts in the contextualised dialogues.

ANOVA and a follow-up Bonferroni Post Hoc test were used to analyse the overall performance and the performance in the comprehension of the direct and indirect speech acts among the groups.

\subsection{Definitions of direct and indirect speech acts and linguistic devices}

In speech act theory, a direct speech act is performed when a speaker makes a literal utterance or locution that performs an illocutionary act (Austin 1962). In contrast, an indirect speech act is performed when a speaker produces a literal utterance that constitutes a secondary illocutionary act that differs from the primary illocutionary act (Searle 1975). In this study, semantic congruence between what is said and what is performed is adopted as the definition of direct speech acts and vice versa for indirect speech acts. Based on these definitions, in this study, the formulaic expressions of 'Can/could I/you', 'May I', 'I was wondering if you could' followed by the request object, which is usually classified as a conventional indirect request in the literature, is glossed as an embedded imperative which belongs to an explicit request with an

\footnotetext{
4 The preliminary survey procedures in Rose's paper (2000) were followed.

${ }^{5}$ I am very grateful to my two research assistants, Patricia and Ka Yu, for their help in completing the survey.
} 
obvious actor, verb and object (Ervin-Tripp 1977). The definitions are further illustrated with two representative questions from the comprehension exercise. Example 1 is an illustration of a direct refusal in which there is semantic congruence between meaning and action: Mei Mei refuses directly by saying 'No, I don't think...'. Example 2 features an indirect act in which the teacher mentions the appropriate required action but the primary illocution act is not stated in the utterance. Interpretation depends heavily on shared knowledge and the context.

Example 1: Direct refusal

12. Fong Fong forgot to do her English worksheet.

Fong Fong: $\quad$ Mei Mei, can I take a look at your English worksheet?

Mei Mei: $\quad$ No, I don't think it is right to do so.

Example 2: Indirect refusal

2. Mei Mei is having an English lesson. She raises her hand.

Mei Mei: $\quad$ Teacher, may I go out?

Teacher After finishing this part.

In the study, a request is glossed as a speech action to request someone to do a favour or perform an action. An apology involves asking forgiveness or apologising for an offensive act. A refusal involves turning down a request or a suggestion. A complaint is a speech act to let someone know that an act is offensive, whereas a compliment involves showing appreciation for an action or event. Similar to the four-feature design of other studies, each question in the exercise consisted of a description of the background or scenario, two turns between the characters, a comprehension question and four response options. To facilitate the comprehension of the response options, the Chinese meaning of a few key vocabulary items were provided.

The linguistic devices and strategies of the speech acts were largely based on features reported in the literature, with the requesting acts being taken from Blum-Kulka, House and Kasper (1989) and Achiba (2003); the apology acts from Blum-Kulka, House and Kasper (1989); the refusal acts from Beebe, Takahashi and Uliss-Weltz (1990) and Félix-Brasdefer (2003, 2004); the compliment acts from Lorenzo-Dus (2001) and Golato (2002); and the complaint acts from Laforest (2002). In addition, reference was made to the formulaic expressions of the respective speech acts recommended by the English Language Curriculum Guide (Curriculum Development Council 2004: 45-46) for Primary 1 to 6 students. For instance, the linguistic device of 'Can I ...?' was borrowed for one of the direct requests and 'Well done' for a direct compliment. At the end of each situation, the participants were asked to determine the meaning of the underlined utterance. Four options were given for each question, only one of which was the most appropriate answer for the specified context. Some words were explained to the participants upon request. A draft of the exercise was presented to 10 primary students in a small-scale study and some cartoon characters added as a result of their feedback on the exercise layout (Appendix 2). ANOVA and the Bonferroni Post Hoc test were used to analyse the correlations between the performance of each group of young L2 learners in the comprehension exercise in the main study. 


\subsection{Think-aloud and verbal protocols with children}

The think-aloud method is a technique that examines what goes on in learners' mind when they perform a given task, for instance comprehension or reading. It can be categorized as concurrent or retrospective think aloud ( $\mathrm{Gu}$, Hu and Zhang 2005). Concurrent think-aloud is a type of verbal report that "consists of stream-of-consciousness disclosure of thought processes while the information is being attended to" (Cohen 1987: 84). The "think-aloud data are usually collected orally from an individual . . . at the moment the thoughts are taking place, with a low degree of formality of elicitation and with little external intervention by the investigator' (Ibid: 88). The potential value of verbal report data from think-alouds has been confirmed in language learning in areas such as uncovering lexical inferencing procedures (Hasstrup 1987) and strategy use with adults (Nassaji 2004; Yoshida 2008) and children (Chamot and El-Dinary 1999; Gu, Hu and Zhang 2005; Young 2005). The usefulness, ability to access mental probes, reliability and acceptability of the data obtained from this source have been questioned by some (e.g., Nisbett and Wilson 1977; Selinger 1983), but Ericsson and Simon argued (1987) that such data are usable, although there are some constraints. Procedures have been suggested to control these constraints and to help respondents who need prodding to produce think-aloud data. These include specific instructions for respondents regarding what to do and how to verbalise thoughts, warm-up activities to acquaint them with the experimental situation and to accustom them to the tape recorders and reminders when they lapse into silence.

Think-alouds have been proved to be a viable data elicitation tool not merely for the description of adults' mental processing and learning strategies but also for young learners' in spite of the fact that it is a labour-intensive technique (Chamot and El-Dinary 1999), the difficulties involved in the elicitation process with children and the common preconception that children are not metacognitively aware of what is going on in their mind or do not have the ability to talk about their interpretation or comprehension processes (Gu, Hu and Zhang 2005). In Chamot and El-Dinary's study (1999), they provided training sessions for the team of researchers and the young learners on the think-aloud technique. The team went through a number of issues, namely the purpose of the study, think-aloud tasks, procedures, questions to ask for clarification and elaboration of the learners' remarks and open-ended prompts to encourage the learners to proceed. On the other hand, the young learners were told how to think aloud either in their L1 or L2 and the procedures to verbalise thoughts for the reading and writing tasks before they began to work on the tasks. The study investigated a total of 72 third- and fourth-grade L2 learners' language learning strategies in Japanese, French and Spanish immersion classrooms in the U.S. and they were compared through match-pairs $t$-tests. The think-aloud verbal reports successfully helped the researchers identify different types of reading and writing learning strategies of the high-rated and the low-rated young $\mathrm{L} 2$ learners. Likewise, $\mathrm{Gu}, \mathrm{Hu}$ and Zhang (2005) who examined the learning strategies of 33 seven- to nine-year-old primary one and three young English learners in Singapore arranged similar training sessions for them. To enhance the effectiveness of the method, the researchers helped the children familiarise with the language tasks and the think-aloud procedures by providing them with a one-hour training session in which the children played the think-aloud games for several language tasks comparable to those that they would be asked to perform. In addition, the researchers showed the equipment and played different games with the 
children so as to establish rapport at the beginning of the session. Finally, the think-aloud data showed that the children were able to use a variety of strategies in learning and using English, and the low-achievers and the high-achievers used different strategies. The identified strategies were illustrated and supported by verbal protocols. $\mathrm{Gu}$, Hu and Zhang felt that the technique is difficult but not impossible to use with primary school students. In another study, Young (2005) used the think-aloud technique to support and enhance her survey, follow-up interview and video-observation findings. She studied the Web-based language learning strategies of five Grade 5 English learners by recording their verbal protocols. Based on the learner's protocols, Young uncovered some learning elements when they were using the Web. These three studies have lent support to two facts. The first is the feasibility to apply the think-aloud technique to reveal information about learning, language use and the strategies young learners use when they are performing some language tasks. The second is that young learners are able to describe their thinking. What is crucial is to use the technique with care $(\mathrm{Gu}, \mathrm{Hu}$ and Zhang 2005: 295).

As the participants of this study were young learners of English whose language proficiency might not allow them to verbalise thoughts in English while working on the exercise, the verbalisation method was modified by asking the bilingual learners to verbalise in their mother tongue (Cantonese), encourage them to continue whenever they fell into silence or paused and keep asking them to explain the decision. The detailed procedure for the verbalisation exercise is presented in Section 6 .

\subsection{Categorising processing strategies}

The participants' processing strategies were coded and categorised according to each of their verbal protocols in an inductive manner. After reading the transcribed protocols, the researcher and the assistant analyzed and categorized the protocols separately according to their shared characteristic features. For instance, protocols that referred to the surface meaning of an utterance were coded under the category of literal meaning and/or formulaic expressions, and were grouped with other processing strategies that attended to semantic meaning and sequential development within an utterance. The processing strategies of adult L2 learners reported in Taguchi's paper (2002), that is, paralinguistic cues, the adjacency pair rule, background knowledge and experience, keyword inferencing, logical reasoning and speaker intention, were used as a reference only, based on the assumption that the cognitive ability of adults and children is necessarily different. Then they compared the categories and finalized the list. The identified processing strategies (Table 7) are by no means an exhaustive list but they

give an indication of young L2 learners' thinking process. The statistical significance of the association between each age group and the identified strategies was computed by means of the Fisher's Exact Test (Table 8), a test for use when the sample size of some items is small.

\section{Procedures}

The participants were selected randomly from each class by the schools. Consent to participate in either (a) the multiple choice comprehension exercise or (b) verbalisation 
were solicited from both the school and parents before the study began. On the day of the research, the participants came to see the researcher and her team in groups according to a planned schedule in a room assigned by the school. One of the team members read the instructions written on the first page of the exercise, explained the examples to the participants and answered any questions that they had. Each participant was given 15 minutes to finish the exercise. While working on the exercise, one out of every six participants was asked to verbalise his or her thoughts in the language of his or her choice (all chose Cantonese). As careful planning and training are significant to the effectiveness of the think-aloud technique (Section 5.3), before the participant verbalised his or her thoughts, the research team played a recording of a verbalisation in Cantonese by a young learner to the participant, explained the procedures and answered any questions. The participant was then given the opportunity to practise once or twice by selecting a question from the multiple-choice comprehension exercise and verbalising his or her thoughts. The research team conducted the study during recess or lunchtime to avoid causing disruption to the learning and teaching activities at the school. The team spent about two to three weeks in each school collecting oral and written data.

A total of $60^{6}$ Primary 2, 4 and 6 young L2 learners (33.71\%) from the three schools agreed to verbalise their thoughts in Cantonese while they were working on the dialogues. Taking into account previous studies on using the think-aloud technique with children (Section 5.3), the verbalisation process consisted of four steps: instruction giving, warm-up, actual verbalisation and reminders. The last two steps overlapped whenever the participant lapsed into silence. To begin with, the researcher briefed the participant on the aims of the study and showed him or her the multiple-choice questionnaire and the tape recorder. The participant then listened to a recording of a seven-year-old Cantonese English learner describing her choice when looking for an answer to a question in the exercise. The researcher then asked the participant in Cantonese to "think and tell me everything that passes through your head during your work when you are looking for an answer to the question. Tell me how you choose the answer as if you were talking to yourself”. After acquainting the participant with the procedure and the tape recorder, he or she was asked to try one question, which gave the researcher the chance to assess whether the participant's verbalisation complied with the instructions. The participant was allowed to ask the researcher the meaning of words that he or she did not know. When the participant fell into silence, the researcher encouraged him or her to keep talking, prompted him or her to explain the choice or sought confirmation retrospectively. When a participant (particularly the seven-year-olds) was unable to say anything, the researcher asked one of the following questions either in Cantonese with some English words (mixed code) or in English, subject to the participant's proficiency level, to find out how they were processing the dialogues.

'Option A, why?' Tell me what you are thinking.'

'What makes you think that $\mathrm{X}$ has made a request?'

${ }^{6}$ They included 23 seven-year-old Primary 2 learners, 20 nine-year-old Primary 4 and 17 eleven-year-old Primary 6 learners from the three schools. 
The recorded protocols were transcribed for analysis, translated and edited (when quoted) (see Appendix 3 for an example of the Cantonese transcriptioni data). The prompts or words uttered by the researcher are presented within parentheses in the quoted protocols.

\section{Findings}

\subsection{Research Question 1: Pragmatic comprehension ability and performance of young L2 learners at different stages of childhood}

The most important finding is evidence of a developmental pattern of pragmatic comprehension ability with age, as reflected by the overall mean scores and the mean scores for the comprehension of the direct and indirect speech acts. The means scores for the three groups of young L2 learners for the whole exercise rose steadily from 6.70 marks to 8.03 and 8.74 marks with age (Table 3).

Table 3: Mean scores for the exercise and statistics for the three age groups

\begin{tabular}{|lllllllll|}
\hline & & & & \multicolumn{5}{l|}{$95 \%$ confidence interval for the mean } \\
Age & $\mathrm{N}$ & Mean & S.D. & Std. Error & Lower band & Upper band & Min. & Max. \\
$7^{7}$ & 64 & $\mathbf{6 . 7 0}$ & 2.623 & .328 & 6.05 & 7.36 & 2 & 10 \\
9 & 62 & $\mathbf{8 . 0 3}$ & 2.142 & .272 & 7.49 & 8.58 & 4 & 11 \\
12 & 50 & $\mathbf{8 . 7 4}$ & 2.508 & .291 & 8.16 & 9.32 & 4 & 11 \\
\hline
\end{tabular}

Key: P2 to P6 = 176 participants; S2 to S6 = 156 participants.

ANOVA and a follow-up Bonferroni Post Hoc test were used to analyse the overall performance and the performance among the groups. The ANOVA test revealed significant differences in the mean scores among the three groups of learners $(F=17.588$, $p=0.000$ ) (Table 4). The Bonferroni Post Hoc test for multiple comparisons further showed a significant difference in the mean scores between the seven- and nine-year-old learners $(p=0.003)$ and the seven- and twelve-year-old learners $(p=0.000)$ but not between the nine- and twelve-year old learners ( $p=.908)$ at the 0.005 level (Table 5).

Table 4: ANOVA - Total number of correct answers across the groups

\begin{tabular}{|llllll|}
\hline & Sum of squares & Df & Mean square & F & Sig. \\
$\begin{array}{l}\text { Between } \\
\text { groups }\end{array}$ & 343.590 & 5 & 68.718 & 17.588 & $\mathbf{0 . 0 0 0}$ \\
$\begin{array}{l}\text { Within groups } \\
\text { Total }\end{array}$ & 1254.159 & 321 & 3.907 & & \\
\hline
\end{tabular}

Key: P2 to P6 = 176 participants.

${ }^{7}$ The Cantonese transcription was based on Fan, Kwok et al. (1997). 
Table 5: Bonferroni Post Hoc test - multiple comparisons of the overall mean scores

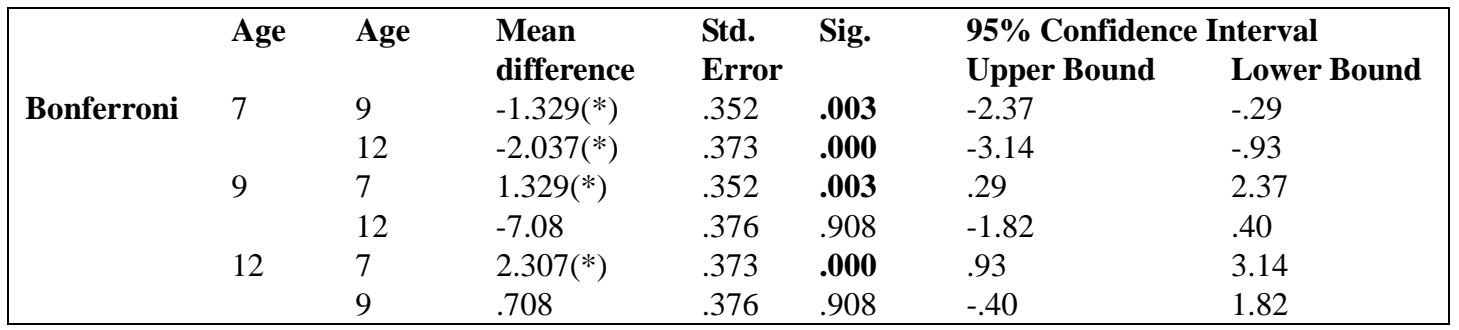

Key: P2 to P6 = 176 participants.

The mean difference is significant at the 0.005 level.

Judging by the performance of the three groups for each question, the participants generally had no difficulty comprehending the direct and some indirect speech acts, and answered nine out of the twelve questions with at least a 50\% accuracy, except for the two indirect refusals, the one indirect compliment and the indirect complaint. A comparison of the relative percentage of correct answers by age reveals that questions 2 and 7 were the relatively more difficult questions, with all three groups achieving less than a 50\% accuracy for these. In addition, the seven-year-old learners answered five questions, the nine-year-old learners three questions and the twelve-year-old learners two questions with a lower than $50 \%$ correctness. The direct speech acts were generally handled well by the three groups of learners, but they all expressed some difficulty comprehending the indirect refusal, complaint and compliment. The breakdown in Table 6 shows that indirect refusal was the most difficult speech act for all three groups to comprehend, and that the indirect complaint and compliment seemed to be rather challenging for the seven- and nine-year-old learners, who completed these questions with a less than $50 \%$ accuracy.

Table 6: Percentage accuracy for each question (sorted by speech act situation)

\begin{tabular}{|c|c|c|c|}
\hline Question & 7-year-olds & 9-year-olds & 12-year-olds \\
\hline \multicolumn{4}{|c|}{ Face-threatening speech acts } \\
\hline \multicolumn{4}{|l|}{ Requesting } \\
\hline 1 (direct) & $80.1 \%$ & $86.2 \%$ & $96.3 \%$ \\
\hline 6 (direct) & $51.6 \%$ & $57.1 \%$ & $82.4 \%$ \\
\hline 11 (indirect) & $70.8 \%$ & $82.5 \%$ & $94.1 \%$ \\
\hline \multicolumn{4}{|l|}{ Refusal } \\
\hline 2 (indirect) & $17.6 \%$ & $32.3 \%$ & $29.4 \%$ \\
\hline $\overrightarrow{7 \text { (indirect) }}$ & $41.5 \%$ & $54 \%$ & $\overline{43.1 \%}$ \\
\hline 12 (direct) & $50.7 \%$ & $69.8 \%$ & $78.0 \%$ \\
\hline \multicolumn{4}{|l|}{ Complaint } \\
\hline 3 (direct) & $47.1 \%$ & $69.8 \%$ & $76.5 \%$ \\
\hline 8 (indirect) & $48.5 \%$ & $\underline{47.6 \%}$ & $54.9 \%$ \\
\hline \multicolumn{4}{|l|}{ Apology } \\
\hline 5 (direct) & $83.1 \%$ & $87.3 \%$ & $88.2 \%$ \\
\hline 10 (indirect) & $88.1 \%$ & $87.3 \%$ & $86.3 \%$ \\
\hline \multicolumn{4}{|l|}{ Compliment } \\
\hline 4 (direct) & $69.1 \%$ & $92.1 \%$ & $96.1 \%$ \\
\hline 9 (indirect) & $32.8 \%$ & $46.0 \%$ & $54.9 \%$ \\
\hline
\end{tabular}

Key: P2 to P6 = 176 participants. /Underlined figures = accuracy percentage below 50\%. 


\subsection{Research Question 2: Processing strategies of young L2 learners at different stages of childhood}

The verbal protocols of 60 of the young L2 learners were examined individually in an inductive manner (Section 5.4). Seventeen single and combined processing strategies were identified, and were grouped into six macro categories based on their characteristic features. The categories were (1) attending to semantic meaning and sequence within an utterance, such as comprehending the literal meaning of the whole utterance or formulaic expressions; (2) attending to the speaker; (3) attending to utterance-answer relations; (4) attending to contextual information; (5) cross-linguistic comparison and (6) personal world knowledge. The definitions of the macro and corresponding sub-processing strategies are summarised and illustrated with representative examples (transcription with edited English version) in Table 7.

Table 7: Definitions and representative examples of the identified macro and sub-processing

$$
\text { strategies }
$$

\section{Attending to semantic meaning and Example}

\section{sequence within an utterance}

1.1 Literal utterance meaning and/or formulaic expression

- A learner comprehends what is said literally by means of fixed formulaic expressions.

1.2 Literal utterance meaning and sequential development

- A learner comprehends what is said literally according to the sequence of information presented in an utterance.

1.3 Cause-result relationship

- A learner reveals the cause of an action and links it with the subsequent result.

1.4 Keyword

- A learner focuses on a keyword in an utterance.

1.5 Sequential development of information and keyword

- A learner examines both information sequence and the keyword(s) in an utterance.
Because when keoi5 keoi5 keoi5 zau4 gong4, keoi5 waa6 'Well done Mei Mei', gam2 zik1 si6 waa6 zaan3 soeng2 gan2 keoi5.

Because when she she she said, she said 'Well done Mei Mei', she was complimenting her. (CH Dai, $11 ; 6, P .6)$

Because keoi5 dou6 hip3 zi1 hau6, zoi3 waa6 bei2 maa1 maa1 ting1 keoi5 zi6 gei2 zing2, zing2 laan6 zo2

Because after apologising, she told her mum that she broke it. (OI Chan, 11;2, P.6)

Jan1 wai6 keoi5 daa1 po3 zo2 hok6 haau6 jat1 baak3 mai5 coi3 paau2 gei3 luk6, keoi5 mma1 mai1 zaan3 keoi5 zou6 dak1 hou1 hou1.

Because she broke the school 100m race record, her mum complimented her on her good performance. (LY Li, 9;3, P.4)

Keoi5 man6 maa3, gam1 can maa3, shut the window, shut maa3.

She asks, can; shut the window, shut.

(HW Choi, 7;1, P.2)

a (dim2 gaai2 hai6 a aa3?) jan1 wai6 keoi5, keoi5 zau6 kei4, kei4 sat6 man6, man6 keoi5 gei2 si4 heoi3 start nei1 go3 eating laa1, gan1zyu6 gam3 zau6 jan1 wai6 Mei Mei ji5 ging1 waan2 zo2 din6 zi2 jau4 hei3 sing4 jat6, sing4 jat6 laa3, gam3 keoi5 zau6 jiu3 tau4 sou3 keoi5 lo1 (ng6, hou2, gam3 nei5 zau6 
gaan2 a, hai6 mai6?) ng6.

A. (Why did you choose ' $a$ '?). In the first place she actually asked her when she would 'start eating' because Mei Mei had played the computer games for the whole day. It was the reason why she had to complain (Right, good, that was why you chose ' $a$ '. Is that right?). Yeah.

(CH Dai, 11;2, P6)

1.6 Partial comprehension of an utterance Jan1 wai6 keoi5 waa6 maa1 mai1 hou5 mong4.

- A learner focuses on part of the Because she said mum was busy. (YS Lau, 7;10, P.2) utterance.

\section{Attending to the speaker}

2.1 Speaker's intention

- A learner infers meaning based on what a speaker intends to say.
2.2 Speaker's feeling

2.3 Speaker's facial expression
Ngo nam2 hai6 'b', jan1 wai4 keoi5 hou3 ci5 soeng2, m4 soeng2 ze3 bei2 keoi5, daan6 jau6 m4 soeng2 zik6 zip3 gong2.

I think it is ' $b$ '. It is because she seems to think, she does not want to lend it to her; but she doesn't want to say it directly. (KS Chan, 11;3, P.6)

Gok3 dak1 keoi5 hai6 teng1 m4 dou2 Fong Fong man6 ke1 je5.

I feel that she cannot hear what Fong Fong asks. (CY Lee, 11;5, P.6)

Jan1 wai6 mum zau6 waa6 'zou6 dak1 hou5 aa1, Mei Mei’. Gan1 zyu6 Mei Mei zau6 siu3, zik1 hai6 Mum hai6 zaan3 soeng2 gan2 keoi5 ke1 biu2 jin6.

Because Mum then said, 'Good job, Mei Mei'. Following this, Mei Mei smiled, because Mum was commending her performance.

(LB Chung, 9;2, P.4)

(so nei5 gok3 dak1 bin1 go3 hai6 daap3 on3 aa3?) a (dim2 gaai2 ge2?) jan1 wai6 Fong Fong $m 4$ gei3 dak1 zou6 gaa1 fo3 zau6 man6 Mei Mei, gan1 zyu6 Mei Mei m4 soeng2 ze3 zau6 giu3 Mary hai2 go2 dou6.

(So, which one do you feel is the answer?) A. (Why?) It was because Fong Fong forgot to do her homework and she asked Mei Mei for help. But Mei Mei did not want to lend her homework to her so she said Mary was over there.

(HY Chan, 7;1, P2)

\section{Attending to utterance-answer relations}

3.1 Utterance-answer keyword match

- A learner matches the meaning of an utterance with the given answers based
Jan1 wai6 keoi5 keoi5 waa6 terrible sorry, gam1 zik1 hai6 doi6 biu2 keoi5 apologise laa1, tung4 maai4 gam1 keoi5 zau6 waa6 I should ask Mum to get you 
on some keywords.

3.2 Repeating the words of the answer

- A learner repeats the words given in the answer.

3.3 Elimination

- A learner decides on an answer by elimination.

\section{Attending to contextual information}

- A learner uses the context to comprehend an utterance.

5. Attending to cross-linguistic comparison

- A learner compares English and Chinese syntax

\section{Personal world knowledge}

6.1 World knowledge

- A learner uses his or her knowledge of the world (e.g., background knowledge) to comprehend the meaning of an utterance.

\section{danc}

Gam1 keoi5 waa6 go1 go3 keep quiet sign, zau6 Well, she showed the keep quiet sign; that's to ask her to keep quiet. (HW Choi, 7;1, P.2)

Can I shut the window? Zek3 hai6 hou5 ci5 hai6 zung3 man4 sau1 ci4 sau2 faat3. Keoi5 m4 hai6 jung6 faan2 man4 geoi3 ... keoi5 hai6 jung6 gan2 ji4 man6 geoi3 gaa1 lo1.

Can I shut the window? That's like Chinese rhetoric. She is not using interrogative and rhetorical questions. She really uses . . . rhetorical questions, she is using interrogative questions.

Jan1 wai6 lou5 si1 ceoi4 si4 gok3 dak1 dim2 gaai2 ni1 loeng5 zoeng1 gung1 zok3 gam2 daap3 on3 hai6 jat1 mou4 jat1 joeng6, gam2 dou3 si4 jyu4 gwo2 lou5 si1 waa6 jiu6 se6 bou2 zai6

Because the teacher will wonder why the answers on the two worksheets are the same. If the teacher spots it, then she will record it in her diary. (WY Wong, 9;9, P.4)

(gam2 lou5 si1 me1 ji3 si1 ne1?) lou5 si1 hai6 waa6, zik1 hai6, Mei Mei hai6 soeng2 waa6 ngo5 ho2 m4 ho2 ji5 heoi3, lai6 jyu4 hai6 heoi3 sai2 sau2 gaan1, gam2 zi1 hau6 go3 teacher zau6 waa6 keoi5, nei5 dang2 maai4, zik1 hai6 gong2 maai4 nei1 jat1 part, gam2 keoi5 nei1 dou6 zau6 d nei1 go3 keoi5 jau6 


\begin{tabular}{|l}
$\begin{array}{l}\text { waa6 tung4 Mei Mei gong2 waa6 jyun4 nei1 jat1 } \\
\text { part sin1 ho2 ji5 gwo3 heoi3 lo1 (ngo5, gam2 so2 ji5 } \\
\text { nei5 gaan2) d (d hai6 mai6?) }\end{array}$ \\
(What does the teacher mean?) The teacher said, that \\
is, Mei Mei said 'May I go out'. For instance Mei \\
Mei wanted to go to toilet. Then the teacher would \\
say you had better wait until she had finished talking \\
about that part. And the scenario matched with D \\
because the answer stated that the teacher asked Mei \\
Mei to finish that part before she could go out. (Oh, \\
so you chose, D (D, right?) \\
(KC Hung, $11 ; 5, P 6)$
\end{tabular}

Among the six macro strategies, the three groups of young learners mainly used category (1) - attending to the information within an utterance (Table 8). The difference in the usage of this strategy among the three groups was found to be statistically significant $(p=0.002)$ at the 0.05 level according to a Fisher's Exact test (Table 9). Of the sub-processing strategies in this category, comprehending the literal meaning or formulaic expressions (63\% on average, Table 10) of the utterance and the sequential development of information (24.67\% on average, Table 10$)$ were dominantly used for comprehending both direct and indirect speech acts. In terms of usage rate, the seven-year-old learners had higher percentage than the other two groups in comprehending the literal meaning or formulaic expression of the utterance but the reverse in attending to sequential development (Table 10). The second most popular macro strategy was category 2 - attending to the speaker, within which the sub-strategy of interpreting speaker intention (88.4\%) was most frequently used. However, the difference in the usage of this category among the three groups was not significant in $(p=.097)$ at the 0.05 level according to a Fisher's Exact test (Table 9). A notable feature of the results is that most nine-year-old and most twelve-year-old L2 learners began to comprehend the speech act of an utterance by using more than one processing strategy. They tended to work out the meaning of an utterance by referring to two processing strategies such as attending to both literal meaning and sequential development (e.g., items 1.2 and 1.5 in Table 7) at the same period of time. A few nine and twelve-year-old learners attended to three processing strategies such as literal meaning, sequential development of the utterances and personal world knowledge of the issue (e.g., items 2.4 and 6.2 in Table 7). Unlike the seven-year-old learners who usually rely on literal meaning or key words when they comprehend a speech act, the other two groups begin to consider a number of clues beyond word level such as context, background knowledge and utterance sequence before coming to or confirming an interpretation. The variety and complexity of identified processing strategies from the three age groups have provided some evidence for the development of young learners' ILP comprehension ability.

For the comprehension of indirect refusals, complaints and compliments, macro categories (1) and (2) continued to be the main choice of the learners (Table 11). The most prevalent sub-strategy in the former category was literal meaning or formulaic expressions, and in the latter category was speaker's intention. Although the frequency of use of category (1) tended to decrease and that of category (2) tended to increase with 
age, the difference among the three groups was not significant at the 0.05 level according to a Pearson's Chi-Square test (Table 12).

Table 8: Frequency rates of Categories 1 to 6 in each age group

\begin{tabular}{|lrlrlrlrl|}
\hline Category & \multicolumn{2}{c}{ 7-year-olds (P2) } & \multicolumn{2}{c|}{ 9-year-olds (P4) } & \multicolumn{1}{c|}{ 12-year-olds (P6) } & Total & \\
& & & & & & & & \\
$\mathbf{1}$ & $\mathbf{1 5 7}$ & $\mathbf{( 6 4 . 1 \% )}$ & $\mathbf{1 3 4}$ & $\mathbf{( 5 9 . 0 \% )}$ & $\mathbf{1 6 5}$ & $\mathbf{( 6 1 . 6 \% )}$ & $\mathbf{4 5 6}$ & $\mathbf{( 6 1 . 6 \% )}$ \\
2 & 40 & $(16.3 \%)$ & 39 & $(17.2 \%)$ & 50 & $(18.7 \%)$ & 129 & $(17.4 \%)$ \\
3 & 35 & $(14.3 \%)$ & 34 & $(15.0 \%)$ & 43 & $(16.0 \%)$ & 112 & $(15.1 \%)$ \\
4 & 10 & $(4.1 \%)$ & 6 & $(2.6 \%)$ & 7 & $(2.6 \%)$ & 23 & $(3.1 \%)$ \\
5 & 0 & $(0.0 \%)$ & 1 & $(0.4 \%)$ & 0 & $(0.0 \%)$ & 1 & $(0.1 \%)$ \\
6 & 3 & $(1.2 \%)$ & 13 & $(5.7 \%)$ & 3 & $(1.1 \%)$ & 19 & $(2.6 \%)$ \\
Total & 245 & $(100 \%)$ & 227 & $(100 \%)$ & 268 & $(100 \%)$ & 740 & $(100 \%)$ \\
\hline
\end{tabular}

Table 9: Difference in category 1 among the three groups by a Fisher's Exact test

\begin{tabular}{|lllll|}
\hline Category & Value & \multicolumn{2}{l|}{ Monte Carlo Sig. } \\
& & Sig. & Lower Bound & Upper Bound \\
1 - Attending to information within an utterance & 24.104 & $\mathbf{. 0 0 2}(\boldsymbol{b})$ & .001 & .004 \\
2- Attending to the speaker & 8.501 & $\mathbf{0 . 9 7}(\boldsymbol{b})$ & .089 & .104 \\
\hline
\end{tabular}

Key: Significant at the 0.05 level.

Table 10: Frequency rates of the six sub-categories of Category 1 in each age group

\begin{tabular}{|c|c|c|c|c|}
\hline Sub-category & $\begin{array}{l}\text { 7-year-old } \\
\text { learners (P2) }\end{array}$ & $\begin{array}{l}\text { 9-year-old } \\
\text { learners (P4) }\end{array}$ & $\begin{array}{l}\text { 12-year-old } \\
\text { learners (P6) }\end{array}$ & Average \\
\hline Literal meaning/formulaic & $108(68.8 \%)$ & 79 (59.0\%) & $101(61.2 \%)$ & $63 \%$ \\
\hline Sequential development & 30 (19.1\%) & 46 (34.3\%) & 34 (20.6\%) & $24.67 \%$ \\
\hline Cause-result relationship & $11(7.0 \%)$ & $6(4.5 \%)$ & $23(13.9 \%)$ & $8.47 \%$ \\
\hline Key word inferencing & $4(2.5 \%)$ & $2(1.5 \%)$ & $5(3.0 \%)$ & $2.33 \%$ \\
\hline Sequential development + key word & $0(0.0 \%)$ & $0(0.0 \%)$ & $2(1.2 \%)$ & $0.40 \%$ \\
\hline $\begin{array}{l}\text { Partial comprehension of the } \\
\text { utterance }\end{array}$ & $4(2.5 \%)$ & $1(0.7 \%)$ & $0(0.0 \%)$ & $1.06 \%$ \\
\hline Total & $157(100 \%)$ & $134(100 \%)$ & $165(100 \%)$ & $100 \%$ \\
\hline
\end{tabular}

Table 11: Processing strategies by question - Indirect refusals (Q2 \& 7), indirect complaints (Q.8) and indirect compliments (Q.9)

\begin{tabular}{|lllll|}
\hline $\mathbf{Q}$ & Category & 7-year-old learners (P2) & 9-year-old learners (P4) & 12-year-old learners (P6) \\
$\mathbf{2}$ & 1 & $\mathbf{2 1 ( 8 0 . 8 \% )}$ & $\mathbf{1 4}(\mathbf{7 7 . 8 \% )}$ & \\
& 1 & $\mathbf{2}(7.7 \%)$ & $\mathbf{3 ( 1 6 . 7 \% )}$ & $\mathbf{1 5}(\mathbf{7 6 . 1 \% )}$ \\
& 2 & $2((7.7 \%)$ & $0(0 \%)$ & $0(0 \%)$ \\
& 3 & $1(3.8 \%)$ & $1(5.6 \%)$ & $0(0 \%)$ \\
$\mathbf{7}$ & 1 & $\mathbf{1 0}(\mathbf{6 2 . 5 \% )}$ & $\mathbf{1 1}(\mathbf{5 2 . 4 \% )}$ & $\mathbf{6 ( 2 6 . 1 \% )}$ \\
& 2 & $\mathbf{4 ( 2 5 \% )}$ & $\mathbf{8 ( 3 8 . 1 \% )}$ & $\mathbf{1 1}(\mathbf{4 7 . 8 \% )})$ \\
& 3 & $2(12.5 \%)$ & $1(4.8 \%)$ & $6(26.1 \%)$ \\
& 6 & $0(.0 \%)$ & $1(4.8 \%)$ & $0(.0 \%)$ \\
\hline
\end{tabular}




\begin{tabular}{|lllll|}
\hline $\mathbf{8}$ & 1 & $\mathbf{1 8}(\mathbf{7 8 . 3 \% )}$ & $\mathbf{1 4}(\mathbf{7 3 . 7} \%)$ & $\mathbf{8}(\mathbf{3 6 . 4 \% )})$ \\
& 2 & $\mathbf{3}(\mathbf{1 3 \% )}$ & $\mathbf{3}(\mathbf{1 5 . 8 \% )}$ & $\mathbf{7}(\mathbf{3 1 . 8 \% )})$ \\
& 3 & $0(0 \%)$ & $1(5.3 \%)$ & $4(18.2 \%)$ \\
& 4 & $2(8.7 \%)$ & $0(0 \%)$ & $3(13.6 \%)$ \\
& 6 & $0(0 \%)$ & $1(5.3 \%)$ & $0(0 \%)$ \\
$\mathbf{9}$ & 1 & $\mathbf{1 3 ( 6 1 . 9 \% )}$ & $\mathbf{1 0}(\mathbf{5 8 . 8 \% )}$ & $\mathbf{1 4}(\mathbf{6 3 . 6 \% )}$ \\
& 2 & $5(23.8 \%)$ & $0(.0 \%)$ & $2(9.1 \%)$ \\
& 3 & $1(4.8 \%)$ & $3(17.6 \%)$ & $5(22.7 \%)$ \\
& 4 & $2(9.5 \%)$ & $4(23.5 \%)$ & $1(4.5 \%)$ \\
\hline
\end{tabular}

Table 12: Pearson Chi-Square test results for indirect refusals (Q2 \& 7), indirect complaints (Q.8) and indirect compliments (Q.9)

\begin{tabular}{|llll|}
\hline Question & Value & Df & Asymp. Sig. (2 sided) \\
2 & 8.059 (a) & 6 & .234 \\
7 & 9.730 (a) & 6 & $\mathbf{. 1 3 6}$ \\
8 & 15.736 (a) & 8 & $\mathbf{. 0 4 6}$ \\
9 & 4.384 (a) & 6 & $\mathbf{. 6 2 5}$ \\
\hline
\end{tabular}

Key: Significant at the 0.05 level.

\section{Discussion}

Two major issues merit further discussion. The first is the young L2 learners' pragmatic comprehension ability and the developmental pattern that stems from it. The second is the relationship between the developmental pattern and the identified processing strategies. The discussion is juxtaposed with the pragmatic development of L1 children and the processing strategies of adult L2 learners.

\subsection{Developmental pattern of young L2 learners' pragmatic comprehension with age}

The comprehension results sketch the developmental pattern of the three groups of young Hong Kong ESL learners' ability to comprehend five direct and indirect speech acts. Their pragmatic comprehension ability increases with age. The young ESL learners demonstrated a steady upward development trend in their pragmatic ability in terms of an increase in mean score with age group (Figure 1). However, according to the follow-up Bonferroni Post Hoc test results for multiple comparisons of accuracy and the direct and indirect speech act comprehension scores, development seems to slow between the ages of nine and twelve year, as the difference in mean score between these two groups was not significant $(p=0.908)$ compared with the significant difference between the seven- and nine-year-olds at the 0.05 level $(p<0.003)$ (Table 5). Nevertheless, the pragmatic development of these groups of young learners of English is close to that of L1 children. The literature shows that children are able to understand indirect speech acts after the age of six because of their cognitive development, increased exposure to language and greater awareness of other ways to express an intention when they interact with adults. Similarly, in this study, the seven-year-old learners had no particular difficulty in understanding direct speech acts and most of the 
indirect speech acts except for indirect refusals, compliments and complaints, none of which occur frequently or are likely to be uttered indirectly in their daily social experience. Comprehension of indirect speech acts is no longer a big problem for the nine- and the twelve-year-old learners.

On the other hand, the relatively weak performances of the three groups in indirect speech act comprehension in contrast to direct speech act comprehension can be interpreted as a reflection of their current L2 linguistic and discourse knowledge of speech acts guided by the official English Language Curriculum Guide (2004) and perhaps amount of classroom instruction in learning the five speech acts and corresponding linguistic devices whose semantic meaning is always congruent with the speaker's intended meaning during their primary education (Section 4.1). The formulaic expressions for speech act communication listed for six to twelve year-old learners in the official document limit the young learners' experience and school instruction in comprehending indirect expressions for various interpersonal communication. Their restricted L2 linguistic devices and knowledge from school instruction may impede their comprehension of the utterances when what is said is incongruent with what is performed.

The literature on the pragmatic competence of L1 children does not specify the extent to which comprehension develops beyond the age of six. The statistical analysis of the three groups of young learners of English seems to provide some provisional evidence on this research gap by showing that comprehension improves significantly from age seven to nine (i.e., early childhood to middle childhood) but then plateaus after age nine (middle childhood) (Table 3 and Figure 1). The rise-then-plateau pattern of these young learners may be influenced by many socio-psychological factors, among them may include school instruction, cognitive development and English proficiency. The information about their English learning experience described in Section 4.1 and the study design do not suffice to give a comprehensive explanation of the developmental pattern or generalise a developmental pattern applicable to all young learners of English. Further investigations into the comprehension of direct and indirect speech acts within the same groups of young learners in both L1 and L2 as well as the relationship between performance and school instruction or learners' English proficiency are required before making a conclusive pattern.

Figure 1: Developmental pattern of the pragmatic comprehension ability of ESL learners with age

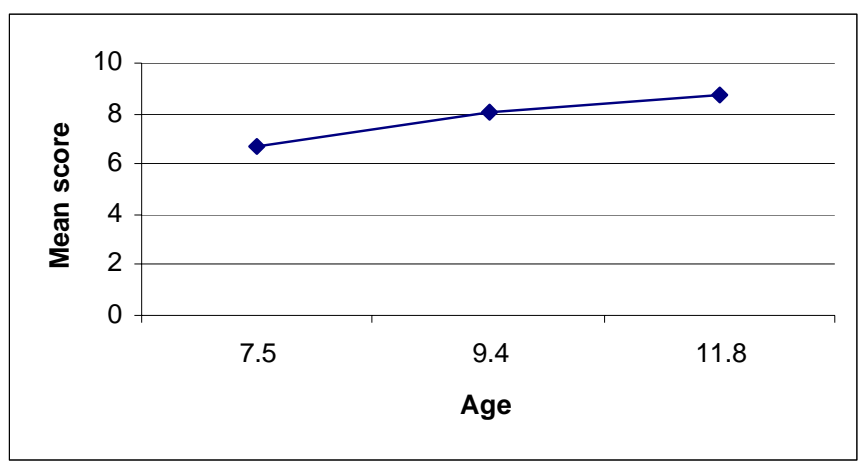




\subsection{Developmental pattern and young L2 learners' processing strategies}

The second issue relates to the young L2 learners' processing strategies. The analysis of the verbal protocols of the young L2 learners in this study shows that they comprehended English in a variety of ways. These can be broadly grouped into six major categories that range from the word level in an utterance to contextual information and their own personal world knowledge. Among these processing strategies, that of attending to meaning - and specifically the literal meaning and formulaic expressions of an utterance - ranks first in terms of frequency of use (Table $10)$, and there is a significant difference in its use among the three groups $(p=0.002$, Table 9), with more seven-year-old learners than nine- and twelve-year-old ones using this strategy (Table 10). Attending to literal meaning seems to be a normal comprehension strategy for young children in early childhood, that is before the age of six, as they are used to reacting to literal statements made by caretakers and parents (Menyuk 1988). In the study, the strategy helps the seven-year-old learners to comprehend direct speech acts because what is said is congruent with what is performed. However, the same strategy does not appear to work well for indirect speech acts, because these acts require a learner to find out the speaker's primary illocutionary act, rather than the secondary illocutionary act conveyed by the uttered statement. Particular difficulty arises in comprehending indirect refusals, compliments and complaints, none of which are speech acts to which young children are often exposed to in their early socialisation. According to the literature on children's L1 pragmatic development, it is only when children are in middle childhood that they are exposed to non-literal or untrue statements in interaction, think about the relationship among words and structures in context, appreciate the meaning of words and produce indirect speech acts (Menyuk 1988). Therefore, indirect speech acts are not usually encountered or learnt in daily interactions before this stage. This claim is supported by the decreasing frequency with which attending to surface meaning of the utterance (Category 1) was used by the participants in this study and the increasing frequency of attending to other macro-categories with age, although the difference among the age groups in the latter case was not significant statistically (Tables 11 and 12). The verbal protocols of the 60 participants, although partial, seem to provide further evidence to support this result. The identified processing strategies give a good account of the upward development pattern of these young L2 learners' comprehension ability. As shown in the sub-processing strategies of Category 1, the younger the learners are, the more reliance they are on attending to literal meaning, key word or part of the utterance (Table 10). In contrast, the older the learners are, the more willing they are to use a range of strategies such as the sub-processing strategy of sequential development (Table 10) or macro strategies of attending to speaker and utterance-answer relationship (Table 8). Their performance is similar to that of low-proficiency adult L2 learners, who rely on keyword inferencing, in contrast to high-proficiency adult learners, who attend to speaker intention and other metalinguistic or conversational rule systems when comprehending implied meaning (Taguchi, 2002). However, the increasing use of other processing strategies (e.g., speaker intention) in place of the category (1) strategies by the older young learners does not seem to be as clear as might be expected in terms of percentage (Table 8). Perhaps the trajectory of these young L2 learners' pragmatic comprehension is initiated earlier in some children than in others or is influenced some unknown socio-cultural factors such as school instruction. Further investigation of this 
issue is necessary.

\section{Conclusion}

To conclude, this exploratory study on the ILP comprehension ability of the three groups of young ESL learners in Hong Kong makes the following preliminary findings. (1) Pragmatic comprehension ability develops in a linear fashion with age; (2) direct speech acts are more easily comprehended by young learners in this age range; (3) indirect speech acts, in particular refusals, complaints and compliments, were relatively more challenging for the youngest learners (seven-year-olds) than for the other two groups and (4) the youngest (seven-year-old) learners seemed to rely more on literal meaning or formulaic expressions than the other two groups. Although unable to provide a complete picture, this study goes some way filling the research gap in the literature on the ILP pragmatic development of young L2 learners. However, more information regarding the developmental pattern and processing strategies of young learners from other places should be sought, preferably supplemented by production data, to verify the findings. Accordingly, data on the pragmatic production of the same five speech acts is currently being collected from the same group of learners in the form of a cartoon production task. The production data thus collected will be analysed and compared with the comprehension data to provide a more comprehensive picture of both aspects of ILP development. Finally, further research on the extent to which comprehension ability is influenced by school instruction or cognitive development in $\mathrm{L} 1$ and L2 is deemed to be necessary.

\section{Acknowledgement}

The study was a two-year General Research Grant project (242507) supported by the Hong Kong Research Grants Council from 2007 to 2009. I am thankful to the school principals, parents and children who kindly agreed to participate in the study.

\section{References}

Achiba, Machiko (2003) Learning to Request in a Second Language: Child Interlanguage Pragmatics. Clevedon, England: Multilingual Matters.

Austin, John Langshaw (1962) How to Do Things with Words. Oxford: Oxford University Press.

Bardovi-Harlig Kathleen (2002) Pragmatics and second language acquisition. In Robert B. Kaplan (ed.), The Oxford Handbook of Applied Linguistics. Oxford: Oxford University Press, pp. 182-192.

Beebe, L., T. Takahashi, and R. Uliss-Weltz (1990) Pragmatic transfer in ESL refusals. In R. Scarcella, E. Andersen and S. Krashen (eds.), Developing Communicative Competence in a Second Language. New 
York: Newbury House, pp. 55-73.

Bialystok, Ellen (1991) Language Processing in Bilingual Children. Cambridge: Cambridge University Press.

Bialystok, Ellen (2001) Bilingualism in Development: Language, Literacy and Cognition. Cambridge: Cambridge University Press.

Blum-Kulka, Shoshana, Juliane House, and Gabriele Kasper (eds.) (1989) Cross-cultural Pragmatics: Requests and Apologies. Norwood, NJ: Ablex Publishing.

Bouton, Lawrence (1992) The interpretation of implicature in English by NNS: Does it come automatically without being explicitly taught? In L.F. Bouton and Y. Kachru (eds.), Pragmatics and Language Learning: Vol 5. Urbana-Champaign, IL: University of Illinois at Urbana-Champaign, pp. 53-65.

Bouton, Lawrence (1994) Can NNA skill in interpreting implicature in American English be improved through explicit instruction? A pilot study. In Lawrence Bouton (ed.), Pragmatics and Language Learning Monograph Series (Vol 5). University of Illinois at Urbana-Champaign: DEIL, pp. 88-109.

Bouton, Lawrence (1999) Developing nonnative speaker skills in interpreting conversational implicatures in English: Explicit teaching can ease the process. In Eli Hinkel (ed.), Culture in Second Language Teaching and Learning. Cambridge: Cambridge University Press, pp. 47-70.

Brown Penelope, and Stephen C. Levinson (1987) Politeness: Some Universals in Language Usage. Cambridge: Cambridge University Press.

Bucciarelli, Monica, Livia Colle, and Bruno G. Bara (2003) How children comprehend speech acts and communicative gestures. Journal of Pragmatics 35: 207-241.

Byrnes, James P., and Barbara A. Wasik (2009) Language and Literary Development: What Educators Need to Know. New York, London: The Guildford Press.

Carrell, Patricia L. (1982) Relative difficulty or request forms in L1/L2 comprehension. In Mary Hines and William Rutherford (eds.), On TESOL '81. Washington, D.C. Teachers of English to Speakers of Other Languages, pp. 141-152.

Chamot, Anna Uhl, and Pamela Beard El-Dinary (1999) Children's learning strategies in language immersion classrooms. The Modern Language Journal 83.iii: 319-338.

Cohen, Andrew D. (1987) Using verbal reports in research on language learning. In Claus Færch and Gabriele Kasper (eds.), Introspection in Second Language Research, Clevedon, Philadelphia: Multilingual Matters Ltd, pp. 82-95.

Cook, Misty, and Anthony J. Liddicoat (2002) The development of comprehension in interlanguage pragmatics: The case of request strategies in English. Australian Review of Applied Linguistics 25: 19-39.

Curriculum Development Council (1997) Syllabuses for Primary Schools: English Language (Primary 
1-6). Hong Kong SAR: The Education Department.

Curriculum Development Council (2004) English Language Education Key Learning Area: English Language Curriculum Guide (Primary 1-6). Hong Kong SAR: The Education and Manpower Bureau.

Ellis, Rod (2003) Task-based Language Learning and Teaching. Oxford: Oxford University Press.

Ericsson, K. Anders, and Herbert A. Simon (1987) Verbal reports on thinking. In Claus Færch and Gabriele Kasper (eds.), Introspection in Second Language Research. Clevedon, Philadelphia: Multilingual Matters Ltd, pp. 24-54.

Ervin Tripp, Susan (1977) Wait for me, roller skate! In Susan Ervin-Tripp and Claudia Mitchell-Kernan (eds.), Child Discourse. New York, Sand Francisco and London: Academic Press, Inc, pp. 165-188.

Fan, Kwok et al. (1997) Guide to LSHK Cantonese Romanization of Chinese characters. Hong Kong: Linguistic Society of Hong Kong.

Félix-Brasdefer, J. César (2003) Declining an invitation: A cross-cultural study of pragmatic strategies in American English and Latin American Spanish. Multilingua 22: 225-255.

Félix-Brasdefer, J. César (2004) Interlanguage refusals: Linguistic politeness and length of residence in the target community. Language Learning 54.4: 587-653.

Golato, Andrea (2002) German compliment responses. Journal of Pragmatics 34.5: 547-571.

Gu, Peter Yongqi, Guangwei Hu, and Lawrence Jun Zhang (2005) Investigating language learner strategies among lower primary school pupils in Singapore. Language and Education 19.4: 281-303.

Haastrup, Kristen (1987) Using thinking aloud and retrospection to uncover learners' lexical inferencing procedures. In Claus Færch and Gabriele Kasper (eds.), Introspection in Second Language Research. Clevedon, Philadelphia: Multilingual Matters Ltd, pp. 197-212.

Holtgraves, Thomas (2007) Second language learners and speech act comprehension. Language Learning 57: 595-610.

Kasper, Gabriele (1984) Pragmatic comprehension in learner-native speaker discourse. Language Learning 34.1: 1-20.

Kasper, Gabriele, and Kenneth R. Rose (2002) Pragmatic Development in a Second Language. Malden \& Oxford: Blackwell Publishing.

Kasper, Gabriele, and Merete Dahl (1991) Research methods in interlanguage pragmatics. Studies in Second Language Acquisition 13: 215-247.

Laforest, Marty (2002) Scenes of family life: Complaining in everyday conversation. Journal of Pragmatics 34.10-11: 1595-1620.

Lorenzo-Dus, Nuria (2001) Compliment responses among British and Spanish university students: A 
contrastive study. Journal of Pragmatics 33: 107-127.

Mckay, Penny (2006) Assessing Young Language Learners. Cambridge: Cambridge University Press.

McLean, James, and Lee Snyder-McLean (1999) How Children Learn Language. San Diego and London: Singular Publishing Group, Inc.

Menyuk, Paula (1988) Language Development: Knowledge and Use. Glenview, Illinois: Scott, Foresman and Company.

Menyuk, Paula, and Maria Estela Brisk (2005) Language Development and Education: Children with Varying Language Experiences. Hampshire and New York: Palgrave Macmillan.

Nassaji, Hossein (2004) The relationship between depth of vocabulary knowledge and L2 learners' lexical inferencing strategy use and success. Canadian Modern Language Review 61.1: 107-134.

Nisbett, Richard E., and Timothy D. Wilson (1977) Telling more than we can know: Verbal reports on mental processes. Psychological Review 84: 231 - 259.

Ochs, Elinor (1979) What child language can contribute to pragmatics. In Elinor Ochs and Bambi Schieffelin (eds.), Developmental Pragmatics. New York: Academic Press, Inc, pp. 1-17.

Olshtain, Elaine (1983) Sociocultural competence and language transfer: The case of apology. In Susan Gass and Larry Selinker (eds.), Language Transfer in Language Learning. Rowley, MA: Newbury House, pp. 232-249.

Rose, Kenneth R. (2000) An exploratory cross-sectional study of interlanguage pragmatic development. SSLA 22: 27-67.

Rose, Kenneth R. (2009) Interlanguage pragmatic development in Hong Kong, phase 2. Journal of Pragmatics 4: 2345-2364.

Schmidt, Richard (1983) Interaction, acculturation, and the acquisition of communicative competence: A case study of an adult. In Nessa Wolfson and Judd Elliot (eds.), Sociolinguistics and Language Acquisition. Rowley, London, Tokyo: Newbury House Publishers, Inc., pp. 137-174.

Schumann, John H. (1978) The acculturation model for second language acquisition. In Rosario C. Gingras (ed.), Second Language Acquisition and Foreign Language Teaching. Virginia: Centre for Applied Linguistics, pp. 27-50.

Searle, John (1975) Indirect speech act. In Peter Cole \& Jerry L. Morgan (eds.), Syntax and Semantics (Vol 3): Speech Acts. New York, San Francisco \& London: Academic Press, pp. 59-82.

Selinger, H.W. (1983) The language learning as linguist: Of metaphors and realities. Applied Linguistics 4.3: 179-191.

Sperber, Dan, and Deirdre Wilson (1995) Relevance: Communication and Cognition (second edition). Oxford, UK \& Cambridge: Blackwell. 
Skehan, Peter (1989) Individual Differences in Second Language Learning. London, New York: E. Arnold.

Snow, Donald B. (2004) Cantonese as Written Language: The Growth of a Written Chinese Vernacular. Hong Kong: Hong Kong University Press.

Taguchi, Naoko (2002) An application of relevance theory to the analysis of L2 interpretation processes: The comprehension of indirect replies. International Review of Applied Linguistics in Language Teaching 40.2: 151-176.

Taguchi, Naoko (2005) Comprehending implied meaning in English as a foreign language. Modern Language Journal 89: 543 - 562.

Taguchi, Naoko (2007) Development of speed and accuracy in pragmatic comprehension in English as a foreign language. TESOL Quarterly 41.2: 313-338.

Taguchi, Naoko (2008a) Cognition, language contact, and the development of pragmatic comprehension in a study-abroad context. Language Learning 58.1: 33 - 71.

Taguchi, Naoko (2008b) The role of learning environment in the development of pragmatic comprehension. SSLA 30: 423 - 452.

Walters, J. (1980) Grammar, meaning, and sociological appropriateness in second language acquisition. Canadian Journal of Psychology 34: 337-345.

Yamanaka, Janice E. (2003) Effects of proficiency and length of residence on the pragmatic comprehension of Japanese ESL learners. Second Language Studies 22.1: 107-175.

Yip, Virginia, and Stephen Matthews (2007) The Bilingual Child: Early Development and Language Contact. Cambridge, U.K., New York: Cambridge University Press.

Yoshida, Mami (2008) Think aloud protocols and type of reading task: The issue of reactivity in L2 reading research. In Melissa Bowles et al. (eds.), Selected Proceedings of the 2007 Second language Research Forum. Somerville, MA: Cascadilla Proceedings Project, pp. 199-209.

Young, Kristy A. (2005) Direct from the source: The value of 'think-aloud' data in understanding learning. Journal of Educational Enquiry 6.1: 19-33. 
Appendix 1: Speech acts, speech situations and social variables used in the questionnaire

\begin{tabular}{|c|c|c|c|}
\hline No. & $\begin{array}{l}\text { Direct/ indirect } \\
\text { speech act }\end{array}$ & Situation/context & $\begin{array}{l}\text { Social variables: social } \\
\text { distance and power hierarchy }\end{array}$ \\
\hline & \multicolumn{3}{|c|}{ Requesting: Asking someone to perform an action/do you a favour } \\
\hline 1 & Direct & $\begin{array}{l}\text { Mei Mei asked her friend Fong Fong if she } \\
\text { could shut the window. }\end{array}$ & $\begin{array}{l}=\text { social distance } \\
=\text { power hierarchy. }\end{array}$ \\
\hline 6. & Direct & $\begin{array}{l}\text { Mei Mei asked Fong Fong if her mum could } \\
\text { take her to the venue for the Speech Festival. }\end{array}$ & $\begin{array}{l}=\text { social distance } \\
=\text { power hierarchy. }\end{array}$ \\
\hline 11. & Refusal: Refusin & $\begin{array}{l}\text { Mei Mei who is a school prefect asked some F. } 1 \\
\text { students to keep quiet while walking up the } \\
\text { stairs to their classrooms. } \\
\text { a request/suggestion }\end{array}$ & $\begin{array}{l}\neq \text { social distance } \\
\neq \text { power hierarchy. }\end{array}$ \\
\hline 2 & Indirect & $\begin{array}{l}\text { Teacher refused Mei Mei's request to leave the } \\
\text { classroom. }\end{array}$ & $\begin{array}{l}\neq \text { social distance } \\
\neq \text { power hierarchy }\end{array}$ \\
\hline 7. & Indirect & $\begin{array}{l}\text { Fong Fong forgot to do her homework and } \\
\text { wanted to borrow Mei Mei's. }\end{array}$ & $\begin{array}{l}=\text { social distance } \\
=\text { power hierarchy. }\end{array}$ \\
\hline 12. & $\begin{array}{l}\text { Direct } \\
\text { Complaint: Comp }\end{array}$ & $\begin{array}{l}\text { Fong Fong forgot to do her English worksheet. } \\
\text { She asked Mei Mei for hers. } \\
\text { ain about an offensive act }\end{array}$ & $\begin{array}{l}=\text { social distance } \\
=\text { power hierarchy. }\end{array}$ \\
\hline 3. & Direct & $\begin{array}{l}\text { Mei Mei told the teacher that Fong Fong hit her } \\
\text { head. }\end{array}$ & $\begin{array}{l}\neq \text { social distance } \\
\neq \text { power hierarchy }\end{array}$ \\
\hline 8. & $\begin{array}{l}\text { Indirect } \\
\text { Apology: Apologiz }\end{array}$ & $\begin{array}{l}\text { Mum was annoyed with Mei Mei's indulgence } \\
\text { in playing computer games. } \\
\text { for an offensive act }\end{array}$ & $\begin{array}{l}\neq \text { social distance } \\
\neq \text { power hierarchy }\end{array}$ \\
\hline 5. & Direct & Mei Mei broke her sister's favorite cup. & $\begin{array}{l}\neq \text { social distance } \\
\neq \text { power hierarchy. }\end{array}$ \\
\hline 10. & Indirect & Mei Mei broke her mother’s pearl necklace. & $\begin{array}{l}\neq \text { social distance } \\
\neq \text { power hierarchy. }\end{array}$ \\
\hline & \multicolumn{3}{|c|}{ Compliment: Show appreciation of an action/effort } \\
\hline 4. & Direct & $\begin{array}{l}\text { Mum praised Mei Mei’s } \\
\text { performance in the Sports Day. }\end{array}$ & $\begin{array}{l}\neq \text { social distance } \\
\neq \text { power hierarchy. }\end{array}$ \\
\hline 9. & Indirect & Fong Fong put on a new dress. & $\begin{array}{l}=\text { social distance } \\
=\text { power hierarchy. }\end{array}$ \\
\hline
\end{tabular}

Key: = with,$\neq$ with no/ without

\section{Appendix 2: Multiple-choice comprehension exercise}

Age:

Class:

\section{Instruction:}

Read the following dialogues between Mei Mei and her friend Fong Fong, the Principal, the teacher and Mum in different situations respectively. Circle the most appropriate 
answer for each situation and finish the task within 10 minutes. An example is given for your reference.

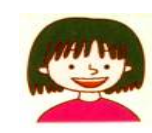

Mei

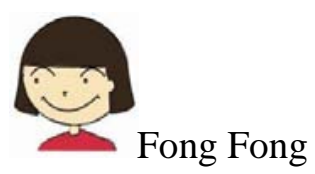

Mei

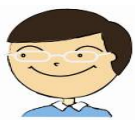

The Principal

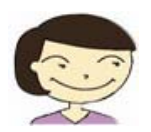

The teacher

Mum

Example

Context: Mei Mei is sitting next to the Principal.

Principal: $\quad$ Can you remind me of your name?

Mei Mei: $\quad$ My name is Mei Mei.

What does the Principal mean?

a. The Principal asks Mei Mei's where she lives.

b. The Principal asks Mei Mei what her name is.

c. The Principal tells Mei Mei to remember her name.

d. The Principal asks Mei Mei to keep quiet.

The answer is (b).

1. Context: Mei Mei is sitting next to the window.

Mei Mei: $\quad$ Can I shut the window?

Teacher: $\quad$ Sure.

What does Mei Mei mean?

a. Mei Mei is asking the teacher to shut the window.

b. Mei Mei is asking the teacher about the window.

c. Mei Mei wants the teacher to know that the weather is cold.

d. Mei Mei wants the window.

2. Context: Mei Mei is having an English lesson. She raises her hand.

Mei Mei: $\quad$ Teacher, may I go out?

Teacher $\quad$ After finishing this part.

What does the teacher mean?

a. The teacher refuses Mei Mei's request.

b. The teacher asks Mei Mei to go out.

c. The teacher wants Mei Mei to be good.

d. The teacher asks Mei Mei to finish that part. 
3. Context: Mei Mei's head was hit by Fong Fong during recess. She met a teacher in the corridor.

Mei Mei: $\quad$ Fong Fong hit me during recess.

Teacher: $\quad$ I'm sorry to hear it.

What does Mei Mei mean?

a. Mei Mei complains to the teacher about Fong Fong's behavior.

b. Mei Mei tells the teacher that she saw Fong Fong during recess.

c. Mei Mei is glad to see Fong Fong during recess.

d. The teacher wants to know what has happened to Mei Mei.

4. Context: Mei Mei broke the school's $100 \mathrm{~m}$ race record in the Sports Day.

Mum: $\quad$ Well done, Mei Mei.

Mei Mei: $\quad$ (smiles)

What does Mum mean?

a. Mum tells Mei Mei to be good.

b. Mum asks Mei Mei to do well.

c. Mum praises (讚賞) Mei Mei’s performance (表現).

d. Mum thinks Mei Mei is feeling well.

5. Context: Mei Mei broke Lily's, her younger sister, favorite cup.

Mei Mei: $\quad$ I'm terribly sorry. I should ask Mum to get you another one.

Young sister: $\quad$ Oh, you should be careful.

What does Mei Mei mean?

a. Mei Mei asks her sister to get another cup from Mum.

b. Mei Mei apologizes (道歎) and suggests (建議) buying a new one.

c. Mei Mei wants her sister to get another cup herself.

d. Mei Mei asks her sister to buy a new cup.

6. Context: Mei Mei and Fong Fong are talking about how to get to the venue for the Speech Festival.

Mei Mei I I wondered if your Mum could take me to the place. My mum is busy.

Fong Fong: $\quad$ No problem.

What does Mei Mei mean?

a. Mei Mei is finding the way to the venue.

b. Mei Mei knows Mum is busy and she will go by herself.

c. Mei Mei asks if Fong Fong goes to the place.

d. Mei Mei asks Fong Fong if her mother can take her to the place.

7. Context: Fong Fong forgot to do her homework.

Fong Fong: Mei Mei, can I borrow your homework?

Mei Mei: $\quad$ Umm...Mary is over there.

Fong Fong: $\quad$ Where? (Mei Mei goes away.)

What does Mei Mei mean?

a. Mei Mei tells Fong Fong that Mary is over there .

b. Mei Mei does not want to lend Fong Fong her homework.

c. Mei Mei thinks Fong Fong wants to play with Mary.

d. Mei Mei cannot hear Fong Fong's question.

8. Context: Mei Mei has played computer games for the whole day.

Mum: $\quad$ Hey, do you think you could start eating?

Mei Mei: $\quad$ In a minute. 
What does Mum mean?

a. Mum complains (投訴) about Mei Mei’s behavior (行為).

b. Mum praises (讚賞) Mei Mei’s behavior.

c. Mum has prepared some food for Mei Mei.

d. Mum asks Mei Mei to eat with her.

9. Context: Mei Mei puts on a new dress.

Fong Fong: $\quad$ Oh, you are like a princess.

Mei Mei: Thanks!

What does Fong Fong mean?

a. Fong Fong likes Mei Mei.

b. Fong Fong praises (讚賞) Mei Mei’s appearance.

c. Fong Fong asks Mei Mei to let her put on the dress.

d. Fong Fong tells Mei Mei that she is a princess.

10. Context: Mei Mei broke her mother's pearl necklace.

Mei Mei: $\quad$ Mum, I don't know that the beads can come out.

Mum: Mmmm.

What does Mei Mei mean?

a. Mei Mei apologizes (道歉) and admit her responsibility (責任).

b. Mei Mei tells Mum that the pearls can come out from the necklace.

c. Mei Mei wants to get the beads from her Mum's necklace.

d. Mei Mei loves her Mum's pearl necklace very much.

11. Context: Mei Mei is a school prefect. Some P.1 pupils are talking while walking up the stairs. There is a keep quiet sign there.

Mei Mei: $\quad$ Do you see the sign?

Classmates: $\quad$ Oh!

What does Mei Mei mean?

a. Mei Mei asks her classmates to keep quiet.

b. Mei Mei wants her classmates to see the sign.

c. Mei Mei shows the sign to her classmates.

d. Mei Mei wants to teach her classmates the two words.

12. Context: Fong Fong forgot to do her English worksheet.

Fong Fong: $\quad$ Mei Mei, can I take a look at your English worksheet?

Mei Mei: $\quad$ Sorry, I don’t think it is right to do so.

What does Mei Mei mean?

a. Mei Mei thinks it is right to help Fong Fong.

b. Mei Mei does not want to lend Fong Fong her English worksheet.

c. Mei Mei apologizes (道歉) to Fong Fong.

d. Mei Mei writes on Fong Fong's English worksheet. 


\title{
Appendix 3: A Cantonese transcription of a retrospective verbal protocol
}

\author{
Question 1 \\ (So2 ji5 what does mei5 mei5 mean?) Mei5 mei5 asks for permission to \\ shut the window. Dim2 gaai2 aa1? Jan1 wai4 mei5 mei5 waa6 ho2 m4 ho2 \\ ji5 hoi1 go3 coeng1, lou5 si1 waa6 ho2 ji5, zik1 hai6 lou5 si1 pai1 zeon2 \\ mei5 mei5 ho2 ji5 hoi1 coeng1 (hai6 laak3, gam3 so2 ji5 a laak3). \\ (So what does Mei Mei mean?) Mei Mei asks for permission to shut the \\ window. (Why?) Because Mei Mei said 'Can I open the window?' The \\ teacher said yes. That is the teacher permits Mei Mei to open the window. \\ A P4 participant's protocol
}

CYNTHIA LEE is an Associate Professor at Language Centre, Hong Kong Baptist University. Her research areas include interlanguage pragmatics, L2 acquisition and English language teaching and learning. She has published two books and articles in international refereed journals.

Address: Language Centre, Hong Kong Baptist University, 224, Waterloo Road, Kowloon Tong, Hong Kong. Fax: 852-3411 7950; e-mail: cfklee@hkbu.edu.hk. 